\title{
Tem Menina no Circuito: dados e resultados após cinco anos de funcionamento
}

Tem Menina no Circuito: data and results after five years

\author{
Gabriella Galdino da Silva ${ }^{1}$, Elis H. C. P. Sinnecker ${ }^{1}$, Tatiana G. Rappoport ${ }^{1,2}$, Thereza Paiva*10 \\ ${ }^{1}$ Universidade Federal do Rio de Janeiro, Instituto de Física, 21941-972, Rio de Janeiro, RJ, Brasil. \\ ${ }^{2}$ Universidade do Minho, Centro de Física, Departamento de Física, QuantaLab, P-4710-057, Braga, Portugal.
}

Recebido em 06 de agosto de 2020. Revisado em 17 de agosto de 2020. Aceito em 18 de agosto de 2020.

\begin{abstract}
Um cenário comum de ser observado nos cursos de ciências exatas de diversas universidades espalhadas pelo Brasil é uma sala composta, majoritariamente, por estudantes masculinos. O que observamos é uma intensa segregação por gênero nas áreas de ensino superior: homens predominam nas ciências exatas, enquanto as mulheres seguem se profissionalizando em ciências da saúde ou educação básica. Alguns aspectos sociais podem contribuir para essa segmentação, como por exemplo, as meninas serem menos expostas do que meninos a assuntos relacionados à Física. Como forma de incentivar meninas estudantes do ensino médio a enxergarem a Física e outras áreas das ciências exatas e naturais como uma oportunidade de carreira, foi criado no ano de 2014 o projeto "Tem Menina no Circuito" que vem sendo desenvolvido desde então. Com o objetivo de entender as influências e contribuições do projeto no período de 2014 a 2019 foi distribuído um questionário às participantes deste. Como uma das conclusões, foi observado que a formação prévia dessas alunas parece ter influência na escolha de suas carreiras profissionais e que o projeto faz com que as alunas vejam outras áreas de atuação como possibilidade, antes desconhecidas por elas.
\end{abstract}

Palavras-chave: Mulheres. Física. Projeto. Ensino.

\begin{abstract}
A common scenario to be observed in the exact sciences courses of several universities around Brazil is a room composed mostly of male students. What we see is intense segregation by gender in higher education areas: men predominate in the exact sciences, while women continue professionalizing in health sciences or basic education. Some social aspects may contribute to this segmentation, such as girls being less exposed than boys to subjects related to Physics. As a way of encouraging female high school students to see Physics and other areas of the exact and natural sciences as a career opportunity, the "Tem Menina no Circuito" project was created in 2014, and has been developed since then. In order to understand the project's influences and contributions from 2014 to 2019 , a questionnaire was distributed to the project's participants. As a conclusion, it was observed that the students' previous education seems to have influence over their career choice and that the project makes the students look to other areas of expertise as possibilities which were previously unknown to them.
\end{abstract}

Keywords: Women. Physics. Project. Teaching.

\section{Introdução}

A ciência deve instigar a curiosidade, a imaginação e a criatividade dos estudantes, resultando em uma fonte de prazer para o aprendizado. Entrando no contexto do ensino de Física nas escolas de ensino médio no Brasil, vemos que os desafios ainda são diversos, porém, o corpo docente cada vez mais se preocupa em dar um sentido para o que está sendo estudado, com o objetivo de mostrar aos estudantes o quão a Física está presente no nosso cotidiano. Um dos resultados do momento atual do ensino de Física é um profundo desinteresse dos alunos pelos conteúdos ensinados em sala de aula e uma insegurança em relação aos conteúdos que serão apresentados ao longo dos anos. Isso pode se dar por conta da ausência de boas

*Endereço de correspondência: tclp@if.ufrj.br experiências ou estímulos com assuntos relacionados à ciência ao longo de sua vida e, como resultado disso, observamos que há um declínio na busca por carreiras nessa área. Para mulheres, além desses fatores, existem questões sociais que contribuem para esse desestímulo.

Com o objetivo de incentivar alunas do ensino médio a escolher carreiras relacionadas às ciências e desmistificar a Física, o projeto Tem Menina no Circuito foi criado em 2014 por três (3) professoras do Instituto de Física da Universidade Federal do Rio de Janeiro (UFRJ) e, desde então, vem atuando em duas escolas do Rio de Janeiro com atividades práticas de circuitos elétricos, promovendo a interação e estimulando a criatividade dessas alunas.

A presente investigação tem como objetivo geral estudar e entender as influências e importância do projeto "Tem Menina no Circuito" na vida das participantes en- 
tre os anos de 2014 e 2019, com a meta de melhorar essa iniciativa. Esse estudo se dá tendo como referência o contexto social de duas escolas públicas de Ensino Médio no Rio de Janeiro, localizadas na Baixada Fluminense. Para a coleta de informações foi distribuído um questionário para as participantes do projeto nesse período e este trabalho apresentará uma análise dos dados coletados a partir dessa pesquisa.

Embora o projeto se restrinja a processos simples que não demandam habilidades específicas dos estudantes, observamos que as dificuldades encontradas estão relacionadas a limites maiores com origens na educação brasileira, na estrutura da sociedade e no próprio projeto educativo que hoje se apresenta para a juventude.

Esse é o contexto no qual foi desenvolvido o projeto e que está sendo discutido aqui em sete seções. As seções 2 e 3 apresentam dados sobre a situação educacional das mulheres e o que contribui para a segmentação de gênero em cursos de Ensino Superior. Na seção 4, o projeto é apresentado. Na seção 5 , a metodologia utilizada para a análise dos dados é detalhada. Na seção 6, os resultados e uma discussão da pesquisa são descritos. Por fim, na seção 7, apresentamos algumas possíveis conclusões.

\section{Alguns dados sobre a situação educacional das mulheres}

Um cenário comum observado nos cursos de ciências exatas de diversas universidades espalhadas pelo Brasil é uma sala composta, majoritariamente, por estudantes masculinos. E no curso de Física isso não é diferente. Dados coletados em 2019 mostram que em um total de 115 docentes do Instituto de Física da UFRJ, apenas 25 são mulheres. Essa desigualdade de gênero se estende ao campo da discência, no qual a porcentagem entre alunos do sexo masculino e do sexo feminino também foge do ideal. Uma análise feita com o número de ingressantes no curso de Licenciatura em Física da UFRJ entre os anos de 1970 à 2019 mostra que o número de alunas não passa de $19 \%$ do total de ingressantes. As Figuras 1 e 2 apresentam o número de ingressantes no curso distribuídos ao longo dos anos e esses mesmos dados em percentual, separado por gênero. Os dados analisados foram extraídos do Sistema Integrado de Gestão Acadêmica (SIGA/UFRJ), sistema no qual apresenta dados referentes ao registro acadêmico.

Ao longo desses anos o curso obteve um saldo total de 2004 ingressantes e destes apenas 382 são mulheres (19\%). A Figura 1 nos mostra que houve um aumento significativo do número de ingressantes no curso de Licenciatura em Física a partir do ano de 1993, isso porque neste ano o curso iniciou uma turma com horário noturno. Antes disso o ingresso era dado após a realização de um concurso e o Instituto de Física ofertava um curso diurno com habilitação em Bacharelado, Licenciatura ou Física Médica e a partir de 1993 a habilitação em Licenciatura diurna foi extinta [1]. Uma observação importante é que

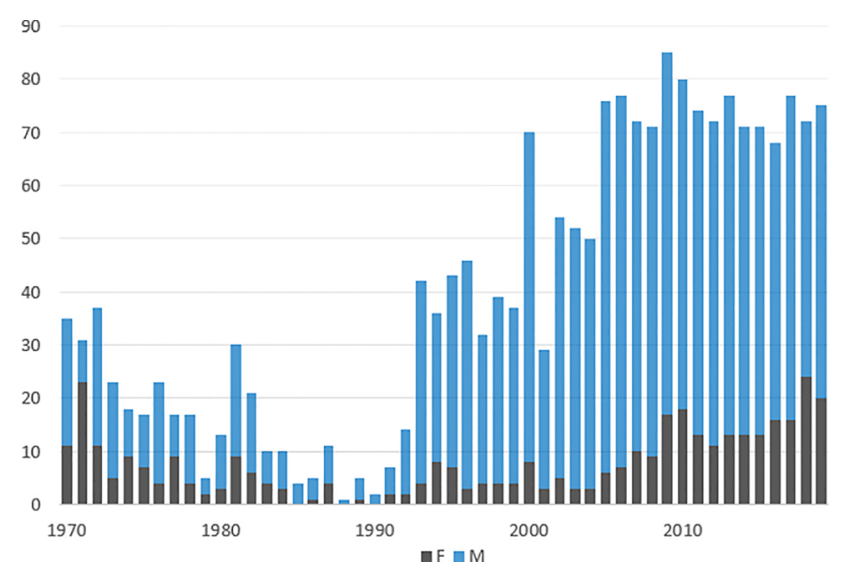

Figura 1: Ingressantes no curso de Licenciatura em Física UFRJ (1970-2019).

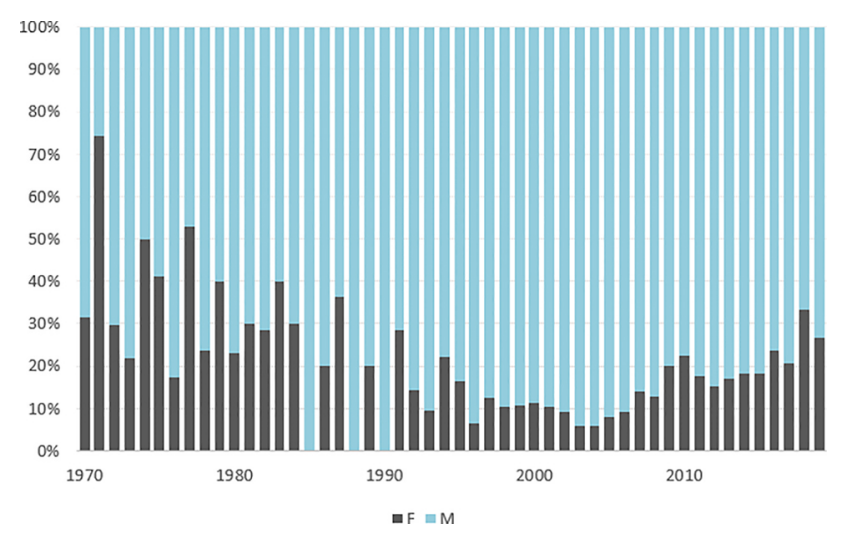

Figura 2: Proporção entre os ingressantes no curso de Licenciatura em Física UFRJ (1970-2019).

entre as décadas de 70 e 90 a quantidade de ingressantes do sexo masculino e feminino era mais próxima, oscilando em torno dos 40\%. Entre os anos de 1990 e 2010 o cenário era bem pior, com cerca de $10 \%$ das vagas sendo preenchidas por mulheres no curso de Licenciatura. Após esse período, mesmo com o número de vagas aumentando, o número de mulheres que ingressaram no curso não passou de $20 \%$, tendo uma melhora nos últimos 4 anos, como por exemplo em 2018, onde esse número chegou a cerca de $30 \%$ do total de ingressantes na graduação. Refletindo sobre a grande evasão entre os cursos de Física da UFRJ, foram coletados os números dos concluintes do curso também entre os anos de 1970 à 2019. A Figura 3 nos mostra uma relação entre os concluintes.

Dos 2004 ingressantes, temos um total de 440 concluintes, dos quais 87 são mulheres (19,8\%). A Figura 3 apresenta flutuações até a década de 90 (onde o curso era diurno) e após isso o número de mulheres que concluem o curso cai e se mantém abaixo de $20 \%$, mostrando o baixo número de professoras de Física se formando para o mercado de trabalho. Buscou-se o entendimento das causas de evasão e baixo número de concluintes por ano no curso de Física. Barroso e Falcão [1] apresentam que alguns motivos estão relacionados com problemas econô- 


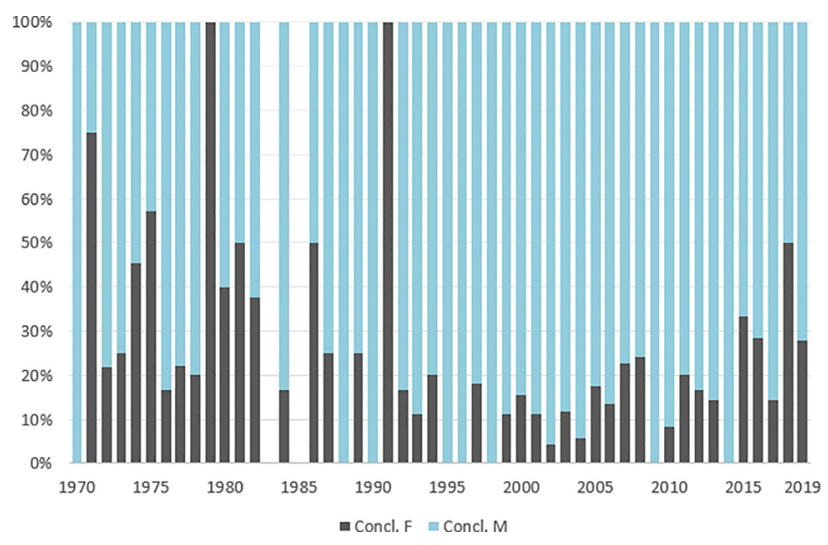

Figura 3: Proporção entre os concluintes no curso de Licenciatura em Física UFRJ (1970-2019)

micos, desinteresse vocacional e problemas institucionais. Para mulheres, os problemas com a instituição, com o corpo docente e discente composto, na sua maioria, por homens pode ser um fator dificultante para a permanência dessas alunas no curso. O fato da Licenciatura em Física tornar-se um curso noturno aparenta também ser um impeditivo para mulheres ingressantes e concluintes, pois de acordo com o gráfico a partir de 1993 o número de alunas que ingressaram oscila em torno de $10 \%$.

Se avaliarmos outras pesquisas, chegamos a conclusão de que esse problema vai além dos muros da UFRJ. A Figura 4 mostra o percentual de homens e mulheres que compõem o corpo docente de Física de algumas universidades do Brasil no ano de 2019. Essas informações foram coletadas das respectivas páginas dos Institutos ou Departamentos de Física das universidades. Esses dados mostram que essa situação se repete por todo o país, onde a participação das mulheres atinge, em média, cerca de $20 \%$ do total de docentes. Em alguns estados a situação é ainda pior, como a UFPB, com uma porcentagem abaixo de $3 \%$.

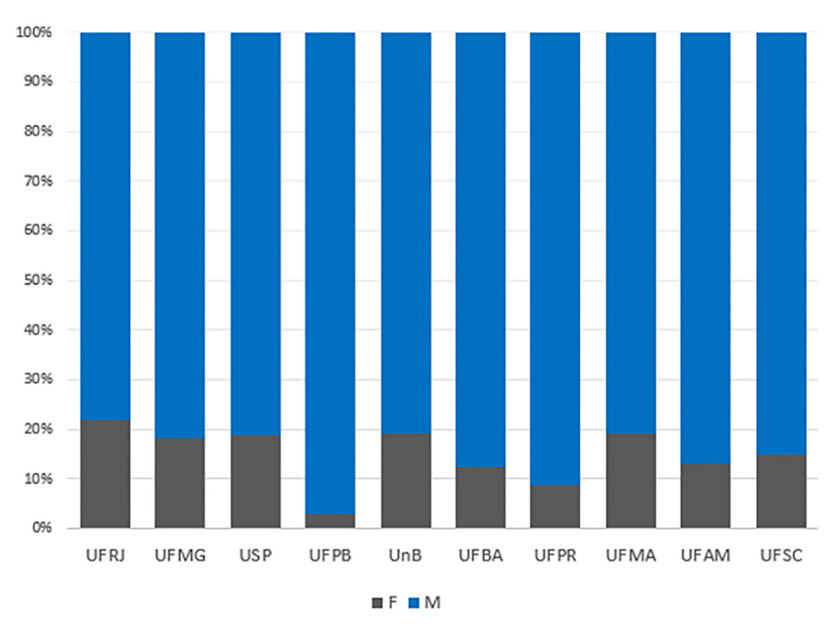

Figura 4: Relação dos docentes de Física
De acordo com estudos do IBGE [2] (Instituto Brasileiro de Geografia e Estatística), o número de mulheres com ensino superior completo excede o número de homens, chegando a mais de $55 \%$. Porém quando comparado os dados distribuídos por cursos os números são bem diferentes. Ou seja, o número de mulheres com diploma é superior ao número de homens, mas poucas dessas mulheres conquistam um diploma na área de ciências exatas e suas tecnologias.

A Figura 5 apresenta alguns dos principais cursos de graduação, ordenados de acordo com o número de matrículas e especificando a participação dos sexos, segundo dados do INEP [3] (Instituto Nacional de Estudos e Pesquisas Educacionais Anísio Teixeira). A Figura 6 mostra que o resultado não se restringe apenas a graduação. Ao analisarmos as matrículas referentes ao mestrado, vemos que a mesma situação se repete.

O que se pode analisar nos gráficos anteriores é um intensa segregação por gênero nas carreiras de exatas,

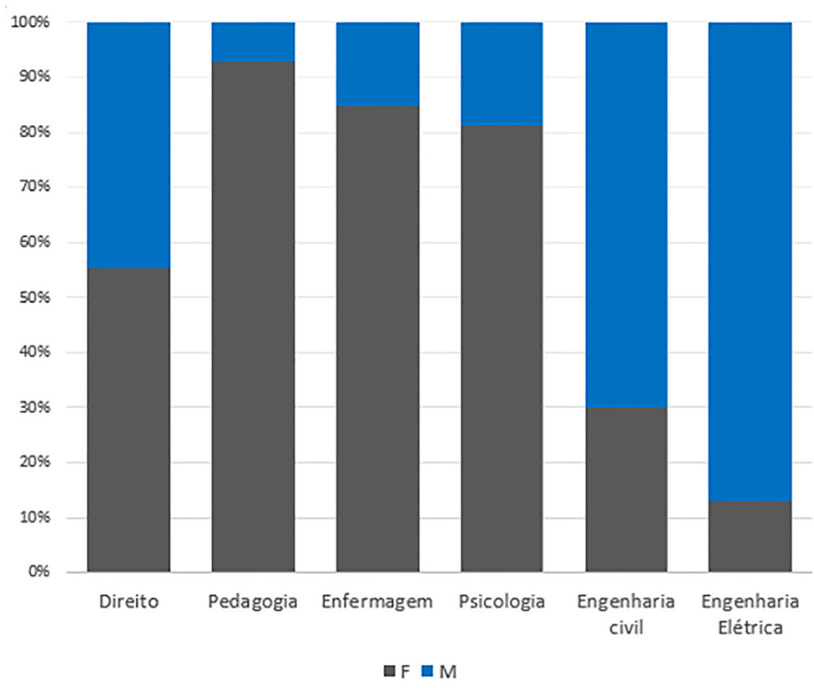

Figura 5: Distribuição de matrículas em cursos de graduação.

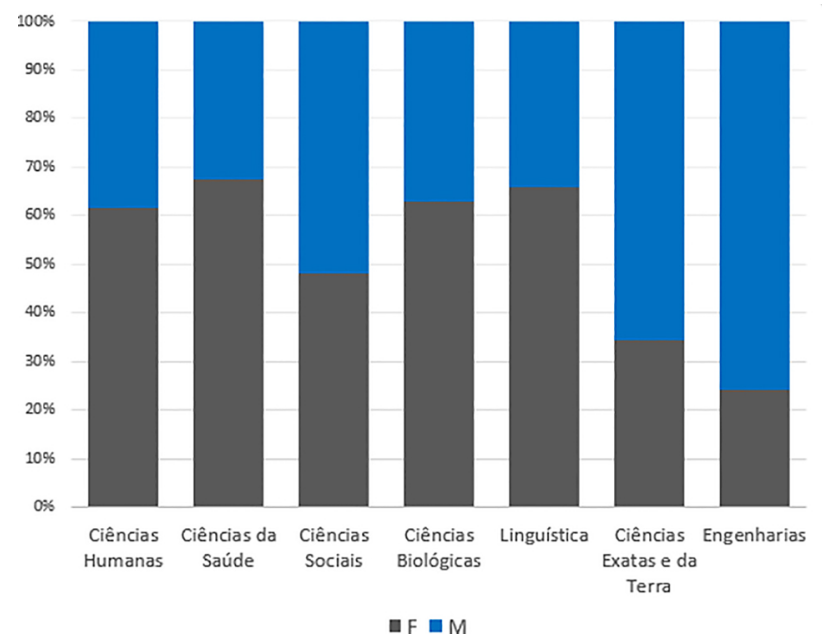

Figura 6: Distribuição de matrículas no mestrado 
saúde e educação: homens predominam nas ciências exatas, enquanto as mulheres seguem se profissionalizando maciçamente, em ciências da saúde ou educação básica. Percebe-se que o baixo índice de mulheres na docência e discência é reflexo de um baixo número de mulheres entrando para a graduação de ciências exatas e suas tecnologias. No entanto, um Relatório publicado pela UNESCO Brasil [4] apresenta resultados mundiais sobre o desempenho em matemática e ciências de meninas e meninos da educação primária e secundária. Os dados comparativos mundiais mostram que meninos e meninas possuem desempenho escolar equivalente em mais da metade dos países, tanto na educação primária quanto na educação secundária, sendo que as meninas saem em vantagem nos testes de ciências, enquanto meninos nos testes de matemática. No entanto, nos resultados onde meninas se saem melhor do que os meninos a diferença de pontuação é significativamente maior do que quando os meninos se saem melhor. Esses resultados indicam que é de suma importância analisar o porquê da segmentação de gênero nos cursos de graduação quando, ainda no ensino médio, ambos os gêneros possuem rendimento equivalente.

\section{O que contribui para essa segmentação de gênero?}

Alguns aspectos sociais e culturais [5 6] podem estar contribuindo para essa segmentação, como por exemplo, os estereótipos socioculturais 7,8, construídos em torno de quais são as habilidades femininas e quais áreas de atuação seriam adequadas para elas frequentemente impostas por familiares e pela mídia. Estudos foram feitos para buscar o entendimento das causas da disparidade de gênero. Estudos realizados em Israel [9], resumem algumas delas: 1) Meninas são menos expostas do que meninos a assuntos relacionados à Física, como por exemplo, brinquedos e hobbies que os ajudam a desenvolver uma base de conhecimentos físicos; 2) A falta de modelos femininos nas ciências faz com que as estudantes não vejam uma relação entre ciência e família, um conceito que parece exercer forte influência nas escolhas das meninas; 3) Uma baixa expectativa de professores e familiares quanto ao desenvolvimento de meninas nas ciências, pois eles também vêem a física como um assunto predominantemente masculino; 4) Os professores dão maior incentivo para que os meninos sigam nas ciências, mais atenção prestadas aos alunos do que às alunas e maior valor atribuído ao que é dito pelos meninos do que ao que é dito pelas meninas; 5) Quanto ao currículo de Física, as meninas expressam maior frustração quando a aula se resume à resolução de problemas baseados na memorização, visto que elas vêem a necessidade de uma contextualização relacionada ao corpo humano ou questões sociais.

Ainda dentro dos aspectos que contribuem para essa segmentação e analisando estudos que levam em consideração a realidade da educação brasileira, um estudo do
Rio Grande do Sul [10] apresenta uma pesquisa realizada com professores (70 mulheres e 14 homens) do ensino fundamental para compreender a visão dos professores sobre as diferenças no desempenho escolar das meninas e meninos. De acordo com os professores entrevistados, as meninas são mais comportadas, dedicadas e sensíveis enquanto os meninos são mais agitados, saem para jogar bola e são mais inteligentes. Quando as meninas não cumprem esse padrão social de comportamento previsto, sua condição sexual é questionada como "Nem parece uma menina". O melhor desempenho das meninas está associado ao bom comportamento e não na construção do conhecimento. O trabalho também conclui afirmando que a condução do processo educativo da criança é construída com estereótipos de gênero, definindo determinados campos como femininos ou masculinos. Entendendo-se que o magistério é uma extensão da maternidade e quando a criança ingressa na escola, ela alimenta suas concepções da representação dos papéis do homem e da mulher na sociedade, vivenciados nas suas relações familiares.

Esses dados ainda não consideram as variações por classes sociais e as situações em que meninas são forçadas a abandonar sua carreira acadêmica por outras questões sociais a que a mulher está exposta como a gravidez precoce, por exemplo. Uma relação entre o jovem brasileiro e a escola diante da precarização da vida, aponta a necessidade de buscar o entendimento da multiplicidade das condições que determinam o "ser jovem" no país, tendo em vista que vivemos em um mundo de desigualdades, violências e oportunidades desigualmente distribuídas conforme a raça, o gênero e a classe social [11]. Os jovens de classes populares, em alguns casos, precisam combinar a rotina de escola e trabalho informal, acarretando em uma indeterminação de trajetória futura. Para as meninas, isso é somado aos fatores de desestímulo encontrados ao longo de sua trajetória. Com isso, nesse quadro de incertezas associadas à conjunturas histórico-políticas instáveis - desconstrução das instituições, ex. CNPq e CAPES, sucateamento das universidades, desemprego estrutural de profissionais graduados - contribuem para que esses jovens desconfiem da força dos diplomas e dos saberes que a escola pode proporcionar.

Além disso, é preciso apontar o cenário em que esses jovens enfrentam a realidade da educação básica no Brasil. A desigualdade de acesso a educação prende muitos jovens a uma vida de desvantagens. Dados do Sistema de Avaliação da Educação Básica de 2017 [12], avaliados pelo INEP, apontam que cerca de $70 \%$ dos estudantes terminam o Ensino Médio sem saber ler um texto simples e sem conhecimentos mínimos de matemática, demonstrando que o Ensino Médio no Brasil tem agregado muito pouco ao desenvolvimento cognitivo dos estudantes brasileiros. Nesse contexto, a formação deficiente desses jovens significa uma menor chance de desenvolvimento das habilidades básicas seja para a vida, seja para a profissionalização ou ainda para o mercado de trabalho. Com esses jovens despreparados e carentes de habilidades 
básicas, apenas sobram possibilidades de ocupações mal remuneradas por não terem sido motivados a melhorar suas perspectivas de emprego, ou por terem enfrentado outras barreiras sociais igualmente significativas.

A Física sempre apresentou um número baixo na representatividade de mulheres na área, [13] com isso cabe a nós nos perguntarmos o porquê de analisarmos esses dados como um problema, ou seja: por que é importante ampliarmos o número de mulheres na física? Podemos obter uma resposta para essa pergunta por dois pontos de vista. Por uma perspectiva social, povoar as ciências com mais mulheres significa proporcionar maior igualdade de oportunidades entre homens e mulheres, considerando as condições de concorrência e acesso a posições de liderança. Por uma perspectiva da ciência, sabemos que a física tem o papel de auxiliar na compreensão do mundo em que vivemos, e a habilidade para a resolução de problemas é fundamental no campo das ciências e em outras áreas como um todo. Uma vez que haja mais mulheres atuando na área, há mais chance de se criar um corpo científico mais competente e renovado pelo fato de homens e mulheres apresentarem experiências de vida e pontos de vista diferentes para contribuir no avanço dos estudos, a ciência também se beneficia com ideias e esforços que ambos podem oferecer 14 .

Leta 15 em um de seus trabalhos faz uma síntese histórica das pesquisas que discutem a participação de mulheres em áreas de Ciência e Tecnologia. Historicamente, a ciência sempre foi vista como uma atividade realizada por homens e a primeira obra mais detalhada sobre a participação e realização de mulheres na ciência foi escrita somente em 1913, por H. J. Mozans, um padre católico. A partir de 1970 essa temática ganhou destaque e importância entre os acadêmicos. Levando em consideração os estudos atuais sobre a relação entre gênero e ciência no Brasil, Gedoz, Pereira e Pavani [16] apresentam uma investigação sobre como as questões de gênero têm sido discutidas na literatura nacional sobre ensino de física entre os anos de 2002 e 2017. Dentre as 9 principais revistas nacionais da área de ensino estudadas, apenas 17 artigos falam sobre a temática, o que ainda mostra um baixo número de estudos nessa área. No contexto das buscas femininas pela inserção nas exatas temos, no início do século XX, a primeira mulher a chegar à posição de professora titular em uma universidade na França e primeira mulher e personalidade a receber duas vezes o prêmio Nobel, um na área de física e outro em química: Marie Curie. Nascida na Polônia, precisou mudar-se para França para seguir seus estudos na área da radioatividade pois teve sua admissão negada na Polônia simplesmente por ser mulher. Além disso, ao receber o prêmio, em 1903, Madame Curie foi injustamente tratada como assistente de pesquisa de Pierre Curie, seu marido, e Henri Becquerel, mesmo todos sabendo que a ideia foi originalmente de Marie Curie 17]. Na atualidade, se não inspirarmos e oferecermos condições de igualdade para as mulheres seguirem na carreira de ciências, talentos como o de Marie Curie podem ser desperdiçados e jamais despertados.

Para contribuir para o acesso de mulheres à carreiras na área de exatas, como a Física, faz-se necessário levar em consideração fatores que influenciam na participação e no desempenho de meninas nas ciências. Agências internacionais como a Organização das Nações Unidas para a Educação, Ciência e Cultura - UNESCO, tem se dedicado a discutir essa questão em suas publicações traduzidas em diversos idiomas. Em uma delas [4] são listados alguns desses fatores, como por exemplo: mais professoras de Física mulheres para servir como figuras exemplares de encorajamento e confiança; tornar as aulas de Física mais atrativas e menos abstratas, oferecendo recursos para um melhor aprendizado; oportunidades iguais entre meninos e meninas de investigação e prática em sala de aula; apoio e motivação familiar atuando desde o início de sua trajetória escolar. Para além desses a escuta às próprias meninas que passam pelo ensino médio é uma contribuição que o presente estudo busca trazer com base na experiência "Tem Menina no Circuito".

Como forma de incentivar meninas estudantes do ensino médio a enxergarem a Física e outras áreas das ciências exatas e naturais como uma oportunidade de carreira, foi criado no ano de 2014 o projeto "Tem Menina no Circuito" que vem sendo desenvolvido desde então. O projeto consiste em atividades práticas de construção de circuitos elétricos com o objetivo de desmistificar a Física e torná-la mais atraente para meninas estudantes, oferecendo-as um conhecimento mais amplo sob uma outra perspectiva, não muito comum. Nesse contexto também lhes são apresentados outros espaços culturais como museus de divulgação científica e laboratórios de pesquisa dos cursos de algumas universidades. Isso amplia de forma mais justa seus direitos de escolha, com o potencial de que o campo das ciências exatas se tornem áreas mais atrativas para o exercício profissional. Seguindo nessa mesma linha, pode-se listar algumas das diversas iniciativas espalhadas pelo país que foram desenvolvidas ao longo dos últimos anos, como por exemplo, o projeto "Meninas Velozes" [18] na Universidade de Brasília, "Meninas na ciência" [19], na Universidade Federal do Rio Grande do Sul, "Mulheres na Ciência da Computação" [20], na Universidade Federal Rural de Pernambuco, e "Engenheiras da Borborema" 21] na Universidade Federal de Campina Grande. Além disso, iniciativas partindo de museus como o projeto "Meninas no Museu de Astronomia e Ciências Afins MAST" e "Meninas nas ciências exatas da Baixada Fluminense" no Museu Ciência e Vida, ambos localizados no Rio de Janeiro. Todos com o intuito de popularizar a ciência e buscar a igualdade de gênero nessas áreas, oferencendo para as alunas participantes um ambiente de acolhimento e aprendizagem, expandindo e melhorando constantemente a inserção da mulheres nas áreas de exatas e tecnologias. 


\section{O projeto}

O projeto Tem Menina no Circuito surgiu no ano de 2014, a partir de uma inquietação de três professoras do Instituto de Física da UFRJ em relação ao relativamente baixo número de mulheres docentes no próprio instituto, representando uma parcela de, aproximadamente, $20 \%$ do total dos docentes. Teve início após a abertura do Edital 18/2013 MCTI/CNPq/SPM-PR/Petrobras - Meninas e Jovens Fazendo Ciências Exatas, Engenharias e Computação, que também possibilitou o desenvolvimento dos projetos "Meninas na Ciência"e "Mulheres na Ciência da Computação", cuja proposta do Edital foi a de realizar financiamento a projetos que visassem estimular a formação de mulheres para as carreiras de ciências exatas, engenharias e computação no Brasil, a fim de combater a evasão que ocorre principalmente nos primeiros anos destes cursos e despertando o interesse vocacional de estudantes do Ensino Médio do sexo feminino.

Em 2016 o projeto contou com o financiamento do edital "Gestão Escolar para Equidade: Elas nas Exatas", do Instituto Unibanco, Fundo Social ELAS e Fundação Carlos Chagas.O projeto "Engenheiras da Borborema"citado anteriormente também foi contemplado com esse financiamento.

Desde então, o projeto Tem Menina no Cirtuito conta com o apoio pessoal dos professores das escolas e coordenadoras do projeto, colocando seus carros à disposição para o transporte das alunas e o projeto segue suas atividades com o estoque de material de consumo. A UFRJ apoia o projeto por meio de bolsas PIBEX para duas monitoras, cada uma frequentando uma das escolas.

No ano de 2014 foram selecionadas 5 meninas do $2^{\circ}$ ano do Ensino Médio do Colégio Estadual Alfredo Neves, localizado em Nova Iguaçu, para participarem das oficinas que seriam realizadas iniciando o projeto. O grupo permaneceu até 2015 , ano em que concluírram o ensino médio. Em 2016 o projeto recomeçou com um novo grupo, iniciando o primeiro contato dessas meninas com conceitos básicos de circuitos elétricos e de programação, estendendo-se até os anos seguintes, ampliando o seu público que passou de 5 para 20 estudantes. Com a expansão das atividades, em 2018 o projeto iniciou a sua participação em mais um colégio na Baixada Fluminense, CIEP 218 Ministro Hermes Lima Brasil-Turquia, localizado em Duque de Caxias, onde as mesmas oficinas são oferecidas. No início de cada ano letivo o projeto é apresentado a todas as turmas do colégio, se mostrando a disposição para quem se interessar e convidando novas alunas a fazer parte da equipe. Hoje o projeto atinge cerca de 30 meninas em 2 escolas.

Nos encontros realizados semanalmente com as alunas são desenvolvidas diversas atividades práticas e interativas que despertam a criatividade delas. Nas oficinas são desenvolvidas atividades como as de circuitos elétricos utilizando materiais simples, como por exemplo: massa de modelar, papel, fita e linha condutoras. Também são realizadas oficinas de mecatrônica em papel, utilizando conteúdo das oficinas de circuitos e também de mecânica. Elas também entram em contato com conceitos de física básica e programação, conhecem alguns componentes eletrônicos, sensores e a placa Arduino. Além do mais, trata-se de um projeto de extensão e inclusão, visto que essas alunas atuam como monitoras, ministrando e divulgando algumas das oficinas para o resto do colégio. Paralelamente a essas atividades, também são realizadas visitas a museus e universidades, com o intuito de proporcionar maior incentivo às meninas ao estarem presentes em espaços de divulgação científica e também vivenciando a rotina de um meio acadêmico, proporcionando uma maior relação com a realidade do mundo universitário e as apresentando outros cursos de graduação que pudessem despertar o interesse em seguir carreiras nessas áreas. As meninas participaram também de eventos sobre mulheres na ciência, como a II Conferência Brasileira de Mulheres na Física, os quais buscavam transmitir posicionamentos críticos relacionados a esse tema, contribuindo desta forma para o desenvolvimento profissional dessas meninas.

Como resultado do primeiro ano de atividades, as meninas participaram da JIC (Jornada Giulio Massarani de Iniciação Científica) na UFRJ em 2014, ganhando menção honrosa apresentando as atividades realizadas por elas ao longo dos encontros. Na turma de 2017, 6 das participantes elaboraram um projeto de mecatrônica em papel o qual foi apresentado na Semana de Integração Acadêmica da UFRJ (SIAC 2017), recebendo novamente menção honrosa.

Os encontros realizados pelo projeto contam com a autoria de monitoras que são alunas de alguns cursos de graduação. Em 2016 e 2017 a monitoria do projeto contou com a colaboração da Gabriella Galdino e Manoela Costa, graduandas no curso de Licenciatura em Física na UFRJ e Design na PUC Rio, respectivamente. Gabriella encerrou suas atividades no Tem Menina no Circuito como aluna em 2015 ao terminar o ensino médio no Colégio Estadual Alfredo Neves. No ano de 2018, o projeto contou com a aluna Mayra Marques no Colégio Estadual Alfredo Neves, cursando Licenciatura em Física, e a aluna Júlia Santos iniciou as atividades no Colégio Brasil-Turquia, cursando Engenharia de Alimentos. Em 2019, a aluna Gabriela Santos, cursando Engenharia da Computação, assumiu as atividades no Colégio Brasil-Turquia.

\subsection{As escolas}

\subsubsection{Colégio Estadual Alfredo Neves - CEAN}

Em 2014, o edital 18/2013 MCTI/CNPq/SPM-PR/Petrobras ofertou uma lista de escolas da qual uma seria selecionada e o critério de escolha das coordenadoras do projeto foi baseado na seleção de um colégio situado em uma região de baixa renda e menos favorecida, visto que dentre os colégios da lista também havia escolas de regiões mais favorecidas. 
A primeira escola selecionada para a implementação do projeto foi o Colégio Estadual Alfredo Neves que fica localizada em uma região de baixa renda no bairro da Posse, em Nova Iguaçu, Rio de Janeiro. Além de não contar com nenhum projeto, um dos professores de Física da escola cursava Mestrado Profissional em Ensino de Física na UFRJ. Trata-se de uma escola Estadual que atende cerca de 320 alunos do ensino médio, apresenta uma estrutura física bem conservada, atendendo às necessidades dos alunos. Comporta 9 salas de aula, 1 biblioteca, 1 laboratório de informática, 1 laboratório de ciências e apresenta um amplo espaço para as atividades físicas e esportivas. A sala de informática possui computadores à disposição, o que contribuiu parcialmente para o andamento de algumas oficinas do projeto por haver dificuldades no acesso a internet.

No ano de 2014 a escola passava por uma transição de ensino regular para o ensino integral, com o Programa Solução Educacional para o Ensino Médio [26]. Com a implementação do Programa, os professores passaram a receber uma gratificação com a finalidade de se dedicarem ao planejamento semanal desse novo projeto. Por conta disso, eram realizadas reuniões pedagógicas semanais com o objetivo de serem realizados planejamentos, criação de projetos e debates sobre o rendimento dos alunos. As reuniões eram realizadas na sexta-feira à tarde e por isso aproveitou-se esse horário para os encontros do Tem Menina no Circuito, visto que nenhuma turma tinha aula nesse horário. Como fruto desses planejamentos semanais, os professores elaboraram em conjunto outras atividades extraclasses para serem desenvolvidas, trabalhando com os alunos exercícios de teatro, horta e jogos educativos. Em 2017 essa gratificação foi cortada, as atividades extraclasses não tiveram continuidade e os tempos de aula foram redistribuídos, ocupando inclusive a sexta-feira à tarde. Hoje, das 9 turmas que a escola possui, 6 passaram a ter aula no horário das oficinas do projeto Tem Menina no Circuito.

No primeiro momento as professoras do projeto apresentar se à coordenação da escola e expuseram os seus objetivos, recebendo apoio de alguns docentes que contribuíram para o desenvolvimento do projeto, dentre eles estão Paulo Henrique, professor de Física e Vanessa Cardeal, professora de Biologia. Hoje o projeto conta com o apoio do professor de Química, Fernando Renato.

\subsubsection{CIEP 218 Ministro Hermes Lima Brasil-Turquia - BRATUR}

Em 2018 o projeto teve a oportunidade de expandir sua atuação para esta segunda escola em Jardim Gramacho, Duque de Caxias. Essa segunda escolha foi feita a partir do contato de um dos diretores da escola, Filipe, com uma das coordenadoras do projeto, Thereza Paiva. O diretor pediu apoio, pois a escola possui "ênfase em Física" com tempos dobrados e período integral. O colégio atende cerca de 330 alunos do ensino médio e também apresenta uma estrutura física bem conservada. Comporta 14 salas de aula, 1 biblioteca, 5 laboratórios, sendo 1 de informática, 1 de artes, 1 de ciências, 1 de idiomas e 1 de turco. Também apresenta um amplo espaço para as atividades físicas e esportivas.

De acordo com a direção da escola, o BRATUR iniciou em 2016 com o Programa Dupla Escola oferecendo uma proposta curricular que visa à formação do estudante desenvolvendo a proficiência na língua estrangeira, valorizando aspectos culturais e a interculturalidade, antes disso o colégio não era intercultural e trabalhava em período regular. Semelhante ao que aconteceu com o CEAN, com a implementação do Programa Dupla Escola, os professores também passaram a receber uma gratificação com a finalidade de se dedicarem ao planejamento semanal desse novo projeto. Os professores realizavam as reuniões pedagógicas semanais na quarta-feira à tarde e esse foi o horário definido para os encontros do Tem Menina no Circuito. Em 2017 essa gratificação também foi cortada, entretanto a coordenação optou por manter esse tempo vago para que os alunos pudessem se dedicar às atividades escolares, o que possibilitou o andamento das atividades do projeto.

Toda a direção da BRATUR é bem envolvida com a escola e isso faz toda a diferença na inserção das atividades do projeto. A partir da implementação do programa, os professores também desenvolveram outros projetos que continuam sendo trabalhados até hoje, abordando as áreas de literatura, exatas e humanas.

Buscando entender a situação do desempenho dessas duas escolas no cenário da educação no Brasil, analisamos os resultados do Índice de Desenvolvimento da Educação Básica (IDEB), calculado a partir dos dados sobre aprovação escolar, obtidos no Censo Escolar, e das médias de desempenho nas avaliações do Inep, o Sistema de Avaliação da Educação Básica (SAEB). A Tabela 1 apresenta um panorama dos resultados comparando os dados das escolas com as médias do Brasil e do Rio de naneiro, usando como referência o $3^{\mathrm{O}}$ ano do ensino médio da rede estadual de ensino no ano de 2017.

A nota geral do Brasil foi de 3,5, um resultado que não alcançou a meta projetada. O Rio de Janeiro encontra-se abaixo da média nacional, com uma pontuação de 3,3. O Colégio Brasil-Turquia formou suas primeiras turmas de $3^{\text {o }}$ em 2018, sendo assim, os resultados referentes ao IDEB e Saeb foram preenchidos com o resultado do ano de $2019\left(^{*}\right)$. Os dois colégios apresentam resultados similares e acima da média nacional, CEAN com 4,5

Tabela 1: Resultados IDEB e Saeb 2017

\begin{tabular}{c|c|c|c|c}
\hline Nome & IDEB & Meta IDEB & $\begin{array}{c}\text { SAEB } \\
\text { Português }\end{array}$ & $\begin{array}{c}\text { SAEB } \\
\text { Matemática }\end{array}$ \\
\hline CEAN & 4,5 & $4,7^{*}$ & 279,53 & 284,19 \\
BRATUR & $4,4^{*}$ & 4,1 & $265,58^{*}$ & $272,87^{*}$ \\
Rio & 3,3 & 4,1 & & \\
Brasil & 3,5 & 3,4 & & \\
\hline
\end{tabular}


e BRATUR com 4,4. Quanto aos dados referentes ao Saeb de Matemática e Português, o BRATUR apresenta uma pontuação que o classifica como nível 2 em ambos e CEAN apresenta nível 3, de acordo com a descrição de níveis apresentada pelo Inep.

\section{Metodologia}

Esta seção descreve os procedimentos metodológicos que guiaram a investigação. Realizou-se uma pesquisa de caráter exploratório do tipo descritivo e abordagem qualitativa, tendo como procedimento técnico uma pesquisaação.

De acordo com Gil 22 existem três tipos de pesquisa: Pesquisa Exploratória, Pesquisa Descritiva e Pesquisa Explicativa. Nesse sentido, a investigação teve como referências metodológicas a pesquisa exploratória.A pesquisa exploratória proporciona ao pesquisador familiaridade com o problema a ser pesquisado, portanto, pode envolver levantamento bibliográfico e entrevistas com sujeitos conhecedores do problema estudado. Desta forma, o estudo buscou ter uma visão geral ou próxima, acerca do sentido que as informações fornecidas pelas participantes do projeto investigado podem ter para uma avaliação do projeto.

Uma pesquisa-ação busca identificar problemas, definir um programa de ação e acompanhar os resultados do ambiente estudado. Segundo Thiollent [23]: "um tipo de pesquisa com base empírica que é concebida e realizada em estreita associação com uma ação ou com a resolução de um problema coletivo e não qual os pesquisadores e participantes representativos da situação ou do problema estão comprometidos de modo cooperativo ou participativo." Sendo um tipo de pesquisa de campo em que o investigador se envolve diretamente com o objeto de estudo, esse trabalho buscou analisar as alterações que o projeto trouxe para o ambiente de vida das participantes.

A metodologia do presente trabalho envolve uma pesquisa que contou com a utilização de um questionário para a coleta de dados direcionado às participantes do projeto no período de 2014 a 2019. A classificação quanto à natureza da pesquisa foi de cunho qualitativo. A abordagem qualitativa buscou evidenciar se houve algum tipo de influência do projeto na vida das participantes, identificando nas respostas do questionário características que indiquem a existência de alguma associação entre a iniciativa do projeto e perspectivas futuras das meninas. Além disso, conhecendo a visão das alunas do ensino médio é possível criar ações para melhorar essa iniciativa.

Para responder a questão central da presente investigação -estudar e entender as influências e a importância do projeto "Tem Menina no Circuito" na vida das participantes- sistematizamos duas questões do questionário seguindo a metodologia do Discurso do Sujeito Coletivo (DSC). Essa técnica nos permite reconstituir, em categorias, representações de um grupo coletivo preservando a sua dimensão individual. Lefevre [24] nos diz que: "O
Discurso do Sujeito Coletivo é uma forma de metodologicamente resgatar e apresentar as representações sociais obtidas de pesquisas empíricas. Nessas, as opiniões ou expressões individuais que apresentam sentidos semelhantes são agrupadas em categorias semânticas gerais."

As representações sociais são códigos que traduzem uma situação social em que o indivíduo está inserido. Ela significa que suas ações condizem com sua realidade e essas representações estão sempre presentes numa opinião, posicionamento, manifestação ou postura de um indivíduo em sua vida cotidiana. A partir dos dados coletados podemos categorizar ideias expostas a fim de representar uma visão compartilhada socialmente dos múltiplos indivíduos em uma única categoria, desenvolvendo, com conteúdo e ideias semelhantes, uma redação em primeira pessoa do singular coerente para um "indivíduo culturalmente equivalente aos pesquisados" 24].

\subsection{Instrumentos para a coleta de dados}

Para a coleta de dados foi distribuído um questionário. Optou-se por usar uma ferramenta que possibilitasse o acesso a todas as alunas e para isso utilizou-se a ferramenta Google Forms para a confecção de um formulário online.

Para alcançar um número representativo de participantes, elaborou-se um questionário eletrônico, não muito extenso e o mais claro possível. O objetivo deste instrumento era obter a opinião das alunas com relação ao seu envolvimento com o projeto. Esse questionário contou com perguntas elaboradas e direcionadas às participantes do projeto desde o início, contendo 17 questões envolvendo o perfil das estudantes, influência do projeto nas suas vidas, preferências, planos e suas expectativas. As alunas foram acessadas e foram enviados 104 convites para participação da pesquisa por meio das redes sociais Facebook e WhatsApp. Fizeram parte dessa pesquisa alunas que já passaram pelo projeto entre os anos de 2014 e 2019. Embora se considere que para uma análise completa dos participantes deve-se abordar também professores e direções das escolas, para fins deste trabalho nos limitamos a uma pesquisa exploratória junto as estudantes.

\subsubsection{Procedimento para a coleta de dados}

Após a elaboração do questionário online realizou-se uma fase de pré-teste, na sua versão preliminar, com uma amostra pequena de participantes ( 5 meninas), com o objetivo de identificar a necessidade de modificações no formato da versão final. Essas meninas foram acessadas por meio das redes sociais Facebook e WhatsApp e, inicialmente, foram convidadas a participar da pesquisa sendo apresentadas ao objetivo e a relevância do estudo, tendo acesso ao endereço eletrônico que as direcionaram para o questionário. Após o pré-teste, realizaram-se pequenas alterações no questionário e, por fim, a versão final foi enviada a todas as meninas que participaram do projeto 
entre os anos de 2014 e 2019. A coleta de dados foi facilitada pela ferramenta Google Forms, que disponibiliza todas as respostas em uma planilha podendo ser acessada online. Após a posse das respostas, foi feita a anállise e sistematização dos dados.

\section{Resultados}

Depois de realizada a coleta de dados da pesquisa, sistematizamos os resultados para fim de análise separados de acordo com as informações fornecidas pelo questionário. Dos cento e quatro (104) convites para o questionário que foram distribuídos, foram obtidas quarenta e quatro (44) respostas de alunas que participaram do projeto entre os anos de 2014 e 2019. A apresentação dos resultados está dividida em: perfil das estudantes, passeios, planos, influência e importância do projeto.

\subsection{Perfil das alunas}

Inicialmente para identificar o perfil das estudantes, uma parte do questionário foi dedicada para conhecer os seguintes aspectos: Escola e Ano escolar, conforme demonstra a Tabela 2 .

De acordo com a Tabela 2, catorze (14) alunas já terminaram o Ensino Médio e trinta (30) ainda estão cursando-o e além disso, das que cursam vinte (20) ainda estão no $1^{\mathrm{O}}$ ano do ensino médio, ou seja, possuem menos de 1 ano no projeto. Por conta disso, viu-se a necessidade de organizar as respostas em dois grupos. Foram organizadas para fim de análise em duas categorias: grupo que finalizou o Ensino Médio (grupo 1) e o grupo que ainda está cursando-o (grupo 2).

O grupo 1 é composto por catorze (14) meninas apenas do Colégio Estadual Alfredo Neves e o grupo 2 por trinta (30) meninas, sendo doze (12) do Colégio Brasil-Turquia e dezoito (18) do Colégio Estadual Alfredo Neves. Como já mencionado anteriormente, o projeto no Brasil-Turquia iniciou-se apenas em 2018 e sem nenhuma aluna de $3^{\text {o }}$ ano do Ensino Médio, isso significa que ainda não temos alunas concluintes nesse colégio para compor o grupo 1 de alunas que já terminaram o ensino médio. Buscou-se identificar a duração dessas alunas no projeto ao longo dos anos de 2014 e 2019. Conforme suas respostas, foi montada a Tabela 3

De acordo com a Tabela 3 , vemos que no grupo 1 temos catorze (14) participantes, sendo que cinco (5) delas permaneceram no projeto durante 1 ano, cinco (5) permaneceram durante 2 anos e quatro (4) durante 3

Tabela 2: Distribuição das alunas por escola e ano

\begin{tabular}{c|c|c|c}
\hline Ano Escolar & CEAN & BRATUR & TOTAL \\
\hline $1^{\circ}$ & 13 & 7 & 20 \\
$2^{o}$ & 2 & 3 & 5 \\
$3^{o}$ & 3 & 2 & 5 \\
Ensino Médio Completo & 14 & 0 & 14 \\
\hline
\end{tabular}

Tabela 3: Distribuição das alunas por escola e tempo de projeto

\begin{tabular}{c|cc|cc}
\hline Ano Escolar & $\begin{array}{c}\text { CEAN } \\
\text { Grupo 1 }\end{array}$ & Grupo 2 & $\begin{array}{c}\text { BRATUR } \\
\text { Grupo 1 }\end{array}$ & Grupo 2 \\
\hline 1 ano & 5 & 17 & 0 & 8 \\
2 anos & 5 & 0 & 0 & 4 \\
3 anos & 4 & 1 & 0 & 0 \\
\hline
\end{tabular}

anos. De acordo com as respostas das alunas, nove (9) permaneceram no projeto até saírem do Ensino Médio e uma (1) dedicou-se ao vestibular no último ano, tendo de 2 à 3 anos de participação. Duas (2) trocaram de escola e duas (2) saíram por conta de outras responsabilidades, ambas permanecendo por apenas 1 ano no projeto. Aproximadamente $65 \%$ das meninas do grupo 1 que participaram da pesquisa permaneceram no projeto até terminarem o Ensino Médio.

No grupo 2, com trinta (30) participantes, temos uma (1) aluna com 3 anos de participação, quatro (4) alunas com 2 anos e vinte e cinco (25) alunas com 1 ano de participação. Quinze (15) dessas alunas ainda permanecem no projeto e quinze (15) delas não participam mais, sendo que catorze (14) são do Colégio Alfredo Neves. Das que saíram, todas mantiveram-se no projeto por apenas 1 ano. Oito (8) delas alegam ter saído por falta compatibilidade de horário, três (3) alegam ter saído por conta de outras responsabilidades, como cursos por exemplo. Quatro (4) não justificaram a saída. Do grupo 2, 50\% das meninas permanecem no projeto atualmente e aproximadamente $27 \%$ não permaneceram apenas por não terem disponibilidade de horário na escola. Na Figura 7 vemos a distribuição de participantes por ano.

Vale comentar sobre a distribuição racial das meninas. Apesar de não ter sido requisitada uma auto declaração nos questionários, acreditamos que o percentual de negras e pardas seja próximo daquele dos muniíciopios onde as escolas estão. Dados do Censo Populacional do IBGE de 2010 28 30 e do Atlas do Desenvolvimento Humano do Brasil 29 31] mostram que em Duque de Caxias 14,5\% da

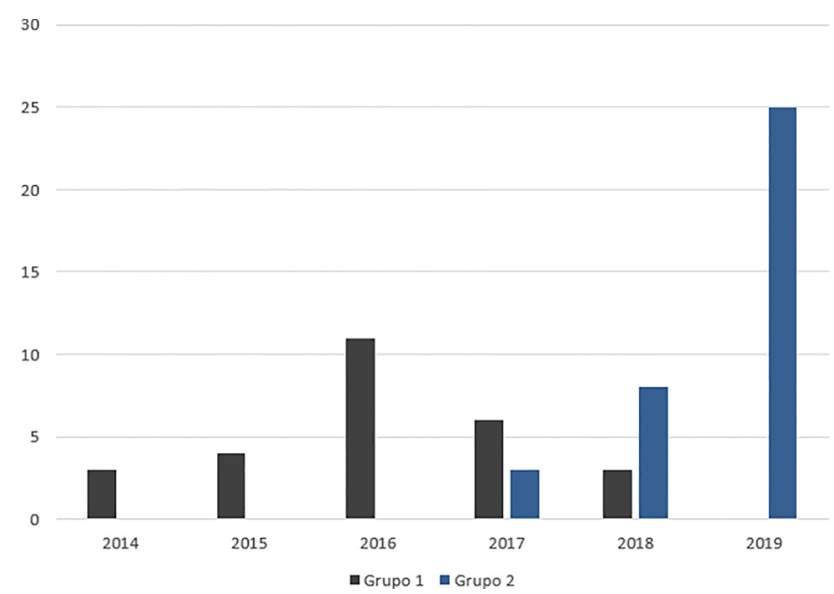

Figura 7: Participantes por ano. 
poulação é negra e $49 \%$ é parda, enquanto que em Nova Iguaçu há 13,6\% de negros e também $49 \%$ de pardos.

\subsection{Passeios}

As alunas também responderam perguntas acerca de suas participações nos passeios realizados pelo projeto. Dentre eles, foram realizadas visitas a espaços de divulgação científica como, por exemplo, universidades, centros de pesquisa e museus de ciências. Suas respostas estão registradas na Figura 8

Um grande número de meninas do grupo 2 não participou de nenhum passeio. Das 14 meninas que responderam nesta categoria, apenas 3 permanecem no projeto. Analisando o número de meninas que saíram do projeto, totalizando 15 alunas, percebeu-se que apenas 6 participaram de passeios. Enquanto no grupo 1, apenas uma aluna não participou de nenhum passeio.

\subsection{Planos antes e depois}

No grupo 1, das 14 participantes, 12 fazem faculdade atualmente e 2 continuam tentando o ingresso, 1 no curso de medicina e outra, trabalhando no momento, tenta engenharia civil. Dessas 12, sete (7) tinham um interesse prévio em alguns cursos de graduação e, com a iniciativa do projeto, conheceram e se interessaram por outras áreas que antes não tinham nenhum envolvimento. Hoje elas migraram de Biologia, Arquitetura, Moda, História e áreas da saúde para Administração, Artes, Letras, Relações Internacionais e Biologia. As outras cinco meninas inicialmente não tinham planos para o futuro e ainda não sabiam o que fazer, porém, depois do projeto passaram a se interessar por algumas áreas, demonstrando interesse inclusive por áreas científicas. Essas meninas fazem hoje Educação Física, Biologia, Letras-Francês e Enfermagem.

No grupo 2, com 30 participantes, todas almejam algo para o seu futuro e alegam estudar para conquistar seus objetivos. Vinte e cinco (25) alunas ainda não decidiram que carreira seguir, mas desejam algum curso de gradu-

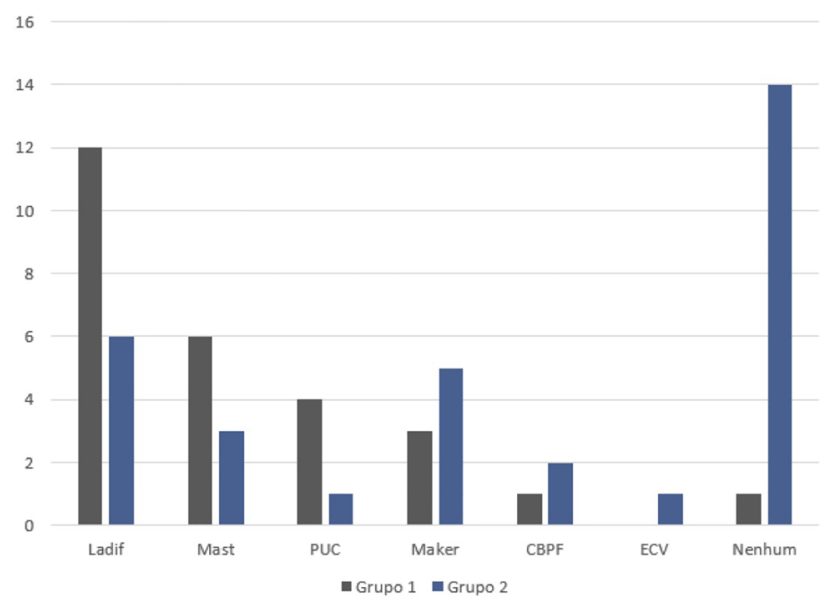

Figura 8: Passeios. ação, enquanto cinco (5) pretendem seguir na carreira militar. Dessas 30 meninas, 15 alunas, oito (8) do CEAN e sete (7) do BRATUR, não sabiam o que queriam fazer ou tinham um interesse prévio em outras áreas. Com a participação no projeto mudaram seus desejos demonstrando interesse em cursar uma faculdade e também pensam como possibilidade seguir carreiras na área científica e de educação. Quinze (15) meninas, sendo 10 do CEAN e 5 do BRATUR, não mencionaram mudanças após sua participação no projeto, onde seus interesses distribuem-se nos cursos de História, Arquitetura, Áreas da saúde e Militar.

\subsection{Influência do projeto}

Para a questão central desta pesquisa, as alunas responderam uma pergunta acerca das influências do projeto na vida delas. Percebeu-se que as respostas continham palavras chaves e ideias semelhantes, por conta disso a sistematização dessa sessão será organizada como Discurso do Sujeito Coletivo das participantes do Tem Menina no Circuito sobre os seguintes temas centrais: I Novos conhecimentos; II Sair da rotina; III Boa; IV Relação afetiva com meio acadêmico; $\mathrm{V}$ Abriu a visão para a Física; VI Aprendizagem; VII Formação pessoal; VIII Despertou interesse por ciências/outras áreas; IX Gênero; X Conhecimento por prestígio e XI Ligação afetiva com a equipe. Observou-se que quanto às influências do projeto, na visão das meninas, não precisamos analisar separadamente o grupo 1 e o grupo 2 pois as contribuições dos dois grupos teve predominância nas mesmas categorias. A partir de ideias centrais relativas às respostas da questão "Comente sobre como foi a influência do projeto nas suas atividades dentro ou fora da escola", foram elaborados os seguintes DSCs:

\subsubsection{Novos conhecimentos}

"O projeto me trouxe um conhecimento sobre uma área a qual eu basicamente não conhecia nada. Me ensinou algo que foi além do conteúdo programático escolar expandindo, dessa forma, meu conhecimento de mundo. Abriu portas para novos conhecimentos, Aprendi que existem diversas formas de introduzir uma matéria e Além de ter adquirido noções básicas de programação, circuito elétrico e todo um conhecimento técnico, também Aprendi mais sobre algumas coisas que eu achava interessante. Haviam coisas que eu não tinha conhecimento e agradeço muito por ter a chance de conhecer. Com o projeto, passei a elaborar melhor minhas ideias e Me influenciou em aprender mais de maneira positiva. Comecei a mudar meu modo de pensar e passei a interagir e gostar. Me trouxe ótimas oportunidades." (Contribuição: 5 formadas, 7 cursando $\mathrm{EM})$ 


\subsubsection{Sair da rotina}

"O projeto me trouxe algo a mais para fazer todas as semanas, algo prazeroso e que eu amava fazer, uma Atividade para sair da rotina da escola."(Contribuição: 1 formada, 1 cursando EM)

\subsubsection{Boa}

"Ótima, Boa." (Contribuição: 1 formada, 1 cursando EM)

\subsubsection{Relação afetiva com meio acadêmico}

"Me fez conhecer mais sobre a UFRJ em si, a qual hoje é minha faculdade e Me levou a ter um contato maior com o mundo acadêmico." (Contribuição: 1 formada, 1 cursando EM)

\subsubsection{Abriu visão para a física}

"Pela dinâmica e aprendizados no projeto encontrei um gosto e Apreço especial pela física. Alimentou meu gosto pela matéria e Abriu minha visão em relação a essa área. O projeto abriu portas para o interesse em conhecer mais da área. Sempre tive bloqueio em física e, com o projeto, pude perceber uma variedade de assuntos interessantes que muitas das vezes não são abordados na sala de aula e com isso Compreendi mais a física. Era maravilhoso, pude olhar a física com outros olhos. Foi uma coisa que eu não esperava ser tão boa, mas me surpreendeu positivamente. O projeto ampliou, positivamente, meus conhecimentos no mundo das exatas e me fez Ter interesse na área. Quando participei do projeto vi que tem muitas coisas legais. Ele foi uma influência boa, porque sempre achei a física muito chata e Os encontros que tivemos me mostrou como a física é na prática, antes eu tinha pensamentos totalmente diferentes." (Contribuição: 5 formadas, 12 cursando EM)

\subsubsection{Formação}

"Contribuiu para minha formação e Passei a elaborar e executar melhor meus projetos, Consegui aplicar o conhecimento que tive através do Tem Menina na minha vida pessoal e escolar." (Contribuição: 1 formada, 2 cursando EM)

\subsubsection{Despertou interesse por ciências/ outras áreas}

"Me influenciou a seguir na carreira da ciência em si. Além dos encontros, das visitas em universidades e nos museus, me interessei em ler e estudar mais sobre mulheres nas ciências. Me incentivou a buscar áreas relacionadas à química. Ele despertou minha paixão pela ciência." (Contribuição: 2 formadas, 2 cursando EM)

\subsubsection{Gênero}

"Sempre tive consciência de que as mulheres sofrem desigualdades perante a sociedade em diversos níveis da vida, mas tive uma conscientização muito maior no campo das ciências exatas e tecnológicas. Por conta do projeto conheci outros programas de incentivo para as mulheres na ciência e percebi que há mulheres incríveis lutando por essa causa, inclusive, claro, o Tem Menina. Ele me mostrou que mulheres podem sim estar envolvidas no meio da ciência, hoje eu curso biotecnologia no Ifrj de são Cristóvão." (Contribuição: 2 formadas)

\subsubsection{Conhecimento por prestígio}

"Obtive ótima experiência explicando para meus pais , minha irmã e meus amigos sobre o que tinha aprendido." (Contribuição: 1 cursando EM)

\subsubsection{Ligação afetiva com a equipe}

"As meninas são fantásticas e ajudam bastante." (Contribuição: 1 cursando EM)

\section{Discussão}

Diante dos resultados obtidos, há alguns pontos que podem ser ressaltados a cerca da influência da atuação do projeto ao longo desses anos, de acordo com as categorias perfil das estudantes, passeios, planos, influência e importância do projeto.

\subsection{Perfil das alunas}

Percebeu-se que no grupo 1 as meninas permaneceram no projeto por mais tempo, com apenas cinco alunas saindo por conta de outras responsabilidades. Já no grupo 2, com as alunas do Colégio Estadual Alfredo Neves, o número de desistências foi alto. Deve-se levar em consideração que nos últimos dois anos a escola passou por mudanças na sua estrutura curricular. Até o ano de 2017 as atividades do projeto se instalaram no turno da sexta feira à tarde, por conta das reuniões pedagógicas semanais que eram realizadas.

Logo, as alunas tinham disponibilidade de horário para participar das oficinas do projeto. A partir de 2017, a maioria das turmas passaram a ter aula nesse horário, o que dificultou a presença das meninas no projeto por não haver um horário que atendesse a todas as turmas. Já no Colégio Brasil-Turquia o projeto não enfrenta problemas com disponibilidade de horário, pois a direção da escola oferece o turno da quarta-feira à tarde para a realização de atividades extraclasses, incluindo as oficinas do Tem Menina no Circuito.

\subsection{Passeios}

O gráfico 7 nos mostra que a quantidade de passeios realizados pelo projeto veio caindo ao longo dos anos, 
pois o grupo 1 tem um número de participações mais elevado que o grupo 2. Deve-se levar em consideração que o último apoio financeiro recebido pelo "Tem Menina no Circuito" foi no ano de 2016 e o projeto vem se mantendo com essa verba até então, contando apenas com apoio dos professores das escolas.

O ambiente de aprendizagem e motivação também se estende para além dos muros da escola. Visitas a museus e laboratórios de faculdade oferecem ótimas oportunidades para aprender e cultivar o interesse das meninas nos assuntos relacionados à ciência, além de promover a interação dessas meninas em atividades fora do cotidiano escolar e, com a ausência dessas atividades fora da escola, todos estes fatores podem ser prejudicados.

\subsection{Planos antes e depois}

Quanto aos planos antes e depois do grupo 1 foi observado que não há uma correlação direta entre o que as participantes tinham como plano inicial de carreira e o que elas fazem hoje. Todavia, é importante ressaltar que nos encontros semanais do projeto algumas alunas demonstravam interesse em seguir carreira militar por interesse dos pais ou por desejo de estabilidade financeira e, por conta disso, esperava-se que essas alunas seguissem essas trajetórias, o que não mostram os resultados encontrados. Uma análise mais profunda dessa categoria está além dos limites dessa pesquisa, exigindo um estudo de caso para identificar os fatores que resultaram nessa mudança.

Além disso, no grupo 1 há alunas que alegam ter pensado em carreira na área de exatas ou ciências como opção, mas por possuírem problemas com matemática, não levaram essa ideia adiante. Percebeu-se que o número de alunas entrando para a área de exatas ainda é pequeno, mas ainda assim não é desprezível, tomando como referência o número de alunas que não responderam o questionário e que estão em cursos na área de exatas ou ainda tentando o ingresso. Além disso, motivar algumas alunas para carreiras nas áreas de ciências exatas e tecnológicas é uma tarefa que ainda enfrenta alguns desafios por estar relacionada com limites maiores relacionados a habilidades específicas das alunas, pois ao escolherem um curso no ensino superior, alegam que possuem dificuldades em matemática e isso torna-se um empecilho para escolha de carreira profissional nessas áreas.

Contudo, o projeto estimula essas alunas a enxergarem outras possibilidades de carreira e algumas se descobrem em outras áreas que com as quais até então não tiveram contato. O contexto da formação prévia e sua influência na escolha de seus planos para o futuro estão relacionados e isso é um fator a ser discutido.

Como a maioria das alunas do grupo 2 ainda se encontram no $1^{\mathrm{o}}$ ano do Ensino Médio, ou seja, estão um pouco distantes da decisão de seus cursos, elas ainda não sabem ao certo que carreiras desejam seguir no ensino superior, entretanto algumas meninas já mudaram suas visões acerca das carreiras no campo científico, demonstrando interesse.

\subsection{Influência do projeto}

A sistematização dos Discursos do Sujeito Coletivo mostra um panorama dos pensamentos das alunas acerca da influência do projeto pela perspectiva delas. Palavras que sintetizam esse discurso são: interesse, conhecimento e aprendizado. Vemos que há predominância nas categorias "Novos Conhecimentos", "Abriu visão para a Física" e "Aprendizagem", evidenciando que há uma relação entre a participação dessas meninas no projeto e o interesse por aprender novas coisas, ajuda para entender melhor os conceitos de física e ter uma melhor relação com a disciplina. Um trecho recolhido nos DSC, na categoria "Abrir a visão para a física", chama a atenção ao demonstrar o novo olhar que as meninas possuem da disciplina depois da participação no projeto: "Pela dinâmica e aprendizados no projeto encontrei um gosto e Apreço especial pela física. Alimentou meu gosto pela matéria e Abriu minha visão em relação a essa área. O projeto abriu portas para o interesse em conhecer mais da área. Sempre tive bloqueio em física e, com o projeto, pude perceber uma variedade de assuntos interessantes que muitas das vezes não são abordados na sala de aula" (DSC, Abrir a visão para a física, 2019).

A fala das alunas aponta que, com a implementação do projeto, elas passaram a ver a física com outros olhos e se interessaram mais pela disciplina, demonstrando que elas passaram a enxergar a importância do estudo da Física. Adquirir novos conhecimentos é algo que ganha destaque nas falas das meninas e demonstra como o projeto as influencia a descobrir e entender novas coisas, além de contribuir para sua formação pessoal: "Havia coisas que eu não tinha conhecimento e agradeço muito por ter a chance de conhecer. Com o projeto, passei a elaborar melhor minhas ideias e Me influenciou em aprender mais de maneira positiva" (DSC, Novos Conhecimentos, 2019).

\subsection{Importância do projeto}

A sistematização dos Discursos do Sujeito Coletivo apresenta um panorama evidenciando a consciência e a avaliação dessas meninas em relação a importância da existência do projeto por uma perspectiva delas. Palavras que sintetizam esse discurso são: conhecimento, incentivo e meninas.

Os DSCs sobre a importância do projeto mostram que as respostas das participantes tiveram predominância nas categorias "Novos Conhecimentos", "Formação Pessoal" e "Gênero".

Um trecho recolhido nos DSC, na categoria "Formação Pessoal", aponta para o projeto como uma forma de incentivo e confiança quanto a capacidade dessas meninas de conquistarem seus objetivos: "Ele foi muito importante 
pois me ajudou a perseverar e acreditar em mim mesma e na minha capacidade. Me incentiva a nunca desistir dos meus sonhos e que eu também sou capaz de chegar onde quero. Ele me estimula a não desistir" (DSC Importância, Formação pessoal, 2019).

A fala das alunas demonstra que o projeto possui um ambiente onde elas recebem um apoio e incentivo da equipe, mostrando que elas são capazes de conquistar o que quiserem.

Os DSC sobre Gênero também ganha destaque na fala das meninas, evidenciando a consciência delas sobre os problemas que existem envolvendo as mulheres na ciência: "O projeto é lindo, pois incentiva as mulheres a fazer ciência, Mostra que é possível E as coloca aonde elas quiserem. [. . .] Ajuda muitas meninas a entrarem na carreira de exatas, área que é vista como "coisa de homem". (DSC Importância, Formação Pessoal, 2019).

Outro destaque sobre a importância do projeto pela perspectiva das alunas está na categoria "Novos Conhecimentos", onde evidencia a necessidade dessas meninas de serem apresentadas as possibilidades de oportunidades que existem para elas: "Ele foi muito importante por me apresentar uma área desconhecida e que eu descobri realmente gostar, Abriu minha mente e também o meu modo de pensar sobre diversas coisas, pois tenho aprendido muito com as meninas [. . . Ime mostrou possibilidades que eu não imaginava. [. . . ] Tenho um grande carinho pelo projeto e acredito que é super necessário, principalmente por mostrar um mundo de possibilidades para meninas da rede pública de ensino. Acho que todos deveriam ter a experiência de viver o Tem Menina do Circuito" (DSC, Novos Conhecimentos, 2019).

\section{Considerações finais}

Diante da pesquisa realizada, há alguns pontos que podem ser ressaltados a cerca da influência da atuação do projeto ao longo desses anos:

- As alunas do grupo 1 permaneceram por mais tempo no projeto, enquanto o Grupo 2 teve um alto número de desistência no CEAN por falta de compatibilidade de horário, o que não foi observado no BRATUR. A política pedagógica da escola teve influência sobre a permanência das meninas no projeto e a falta de disponibilidade de horários é um empecilho para a continuidade das atividades;

- A realização de visitas a museus e laboratórios podem ter contribuído para uma melhor interação do grupo 1 nas atividades oferecidas pelo projeto;

- Quanto às escolhas de atuação profissional, ficou claro que o número de alunas que vem para a área das exatas ainda é pequeno. Entretanto, o projeto faz com que as alunas vejam outras áreas de atuação como possibilidade, antes desconhecidas por elas;

- A formação prévia dessas alunas parece ter influência na escolha de suas carreiras profissionais. Mas um fato é que problemas com matemática podem constituir um obstáculo a escolha de formação e atuação profissional na área de exatas. Isso leva a uma reflexão sobre a necessidade de trabalhar com essas alunas outros aspectos nas oficinas realizadas que abordem o desenvolvimento de suas habilidades básicas;

- Sobre a influência do projeto na vida das meninas, de acordo com os DSC, há uma relação entre a implementação do projeto e um melhor envolvimento com as atividades relacionadas à física. Além disso, por ser um projeto extraclasse, faz com que as meninas entrem em contato e se envolvam com outras atividades adquirindo novos conhecimentos que vão contribuir para o desenvolvimento delas;

- Sobre a importância do projeto para as meninas, os DSC indicam que o Tem Menina no Circuito abriu um espaço onde as meninas se sentem confiantes e incentivadas quanto à sua capacidade de realizar os seus desejos. As meninas também vêem a importância do projeto como uma necessidade para que as mulheres se sintam incentivadas e para mostrar que elas podem fazer o que quiserem. Além disso, as meninas alegam que o projeto é importante por apresentá-las uma área desconhecida por elas, mostrando-as possibilidades que antes elas não viam como oportunidade de desenvolvimento;

Com base nos resultados encontrados nesta pesquisa, observam-se algumas implicações que podem favorecer para a melhoria do desenvolvimento do projeto. Pode-se sugerir:

- Pensar estratégias para a estimular a permanência das alunas, buscando evitar a evasão no projeto;

- Desenvolver um procedimento para coleta de dados acerca das informações das participantes, contribuindo para registros e uma avaliação contínua do que está sendo desenvolvido pelo projeto;

- Elaborar um planejamento anual das atividades para que se possa ter um controle do desenvolvimento das habilidades e competências das participantes.

\section{AGRADECIMENTOS}

Agradecemos ao CNPq e ao Edital Elas nas Exatas pelo financiamento do projeto. Agradecemos ao Maurício Pamplona Pires por fornecer dados do curso de Licenciatura do Instituto de Física da UFRJ.

\section{Referências}

[1] M.F. Barroso e E.B.M. Falcão, em Proceedings do IX Encontro Nacional de Pesquisa em Ensino de Física (Jaboticatubas, 2004).

[2] IBGE - Instituto Brasileiro de Geografia e Estatística, Estatísticas de Gênero - Indicadores sociais das mu- 
lheres no Brasil, disponível em: ibge.gov.br/estatisticas/multidominio/genero/20163- estatisticas-de-generoindicadores-sociais-das-mulheres-no-brasil.html, acessado em 09/08/2020.

[3] INEP - Instituto Nacional de Estudos e Pesquisas Educacionai Anísio Teixeira, Censo da Educação Superior, disponível em: portal.inep.gov.br/web/guest/educacaosuperior, acessado em 9/08/2020.

[4] UNESCO, Decifrar o código: educação de meninas e mulheres em ciências, tecnologia, engenharia e matemática (STEM) (UNESCO, Brasília, 2018).

[5] K. Foote e R. Garg, Rev. Bras. Ensino Fís. 37, 1309 (2015).

[6] E.J.S. Pinto, V.G. de Amorim e M.E.P. de Carvalho, Diversidade e Educação 4, 13 (2017).

[7] A.B. Costa, R.O. Peroni, E.S de Camargo e H.C. Nardi, Sex Res Soc Policy 12, 261 (2015).

[8] J. Leta, Revista Feminismos 2, 139 (2014).

[9] A. Zohar e B. Bronshthein, International Journal of Science Education 27, 61 (2005).

[10] C.A.D. da Silva, F.B.E.S.C. Halperini e L.A.D. da Silva, Cadernos de Pesquisa, 107207 (1999).

[11] P. Carrano, O jovem brasileiro e a escola diante da precarização da vida e de desaftos democráticos, disponível em: https://paulocarrano.blog/2019/09/04/ojovem-brasileiro-e-a-escola-diante-da-precarizacao-davida-e-de-desafios-democraticos/.

[12] Instituto Nacional de Estudos e Pesquisas Educacionais Anísio Teixeira, Relatório SAEB 2017, Instituto Nacional de Estudos e Pesquisas Educacionais Anísio Teixeira, Brasília (2017).

[13] S.M.C. Cartaxo, Gênero e ciência: um estudo sobre as mulheres na física. Dissertação de Mestrado, Universidade Estadual de Campinas, Campinas (2012).

[14] D. Agrello e R. Garg, Rev. Bras. Ens. Física 31, 1 (2009).

[15] J. Leta, Estud Av 17, 271 (2003).

[16] L. Gedoz, A.P. Pereira e D.B. Pavani, em XVII Encontro de Pesquisa em Ensino de Física (Campos do Jordão, 2018).

[17] G. Pugliese, Rev. Antropol. 50, 347 (2007).

[18] D. Viana, Revista Interdisciplinar de Pesquisa em Engenharia 2, 1 (2015).

[19] C. Brito, D. Pavani e P. Lima Jr, Revista Gênero 1, 33 (2015).

[20] C.T.A.P. Queiroz, M.E.P. Carvalho e J.A. Moreira, em $18^{\circ}$ Rede Feminista Norte e Nordeste de Estudos e Pesquisa sobre a Mulher e Relações Gênero. Gênero e inclusão de jovens mulheres nas ciências exatas, nas engenharias e na computação (Recife, 2014).

[21] IEEE - Instituto de Engenheiros Eletricistas e Eletrônicos, Engenheiras da Borborema, disponível em: https://site.ieee.org/sb-ufcg-wie/engenheiras-daborborema/, acessado em 31/07/2020.

[22] A.C. Gil, Como Elaborar Projetos de Pesquisa (Atlas, São Paulo, 2002), $4^{\mathrm{a}}$ ed.

[23] M. Thiollent, Metodologia de pesquisa-ação (Cortez, São Paulo, 2007), 15 $5^{\mathrm{a}}$ ed.

[24] F. Levefre e A.M.C. Lefevre, Texto Contexto Enferm 23, 502 (2014).

[25] S.L. Mathias e C. Sakai, Utilização da Ferramenta Google Forms no Processo de Avaliação Institucional: Estudo de Caso nas Faculdades Magsul, disponível em: https://docplayer.com.br/92880Utilizacao-da-ferramenta-google-forms-no-processo-de-avaliacao-in (2013).

[26] A.C. de O Mendes, Revista da SBEnBio 9, 3751 (2016).

[27] J.G. Rodrigues, Gênero, Ciência \& Tecnologia e Saúde: apontamentos sobre a participação feminina na pesquisa na Fundação Oswaldo Cruz. Tese de Doutorado, Fundação Oswaldo Cruz, Instituto de Informação Científica e Tecnológica em Saúde, Rio de Janeiro (2014).

[28] https://cidades.ibge.gov.br/brasil/rj/duque-decaxias/panorama, acessado em 16/08/2020.

[29] http://atlasbrasil.org.br/2013/pt/perfil/duque-decaxias, acessado em 16/08/2020.

[30] https://cidades.ibge.gov.br/brasil/rj/nova-iguacu/panorama, acessado em 16/08/2020.

[31] http://atlasbrasil.org.br/2013/pt/perfil/nova-iguacu, acessado em 16/08/2020. 